\title{
BMJ Open Complementary medicine in orthopaedic and trauma surgery: a cross- sectional survey on usage and needs
}

\author{
Anica Kilper, ${ }^{1}$ Alexander Müller, ${ }^{2}$ Roman Huber, ${ }^{2}$ Niklas Reimers, ${ }^{1}$ Ludwig Schütz, ${ }^{1}$ \\ Ann-Kathrin Lederer (D) ${ }^{2,3}$
}

To cite: Kilper A, Müller A, Huber R, et al. Complementary medicine in orthopaedic and trauma surgery: a cross-sectional survey on usage and needs. BMJ Open 2020;10:e037192. doi:10.1136/ bmjopen-2020-037192

- Prepublication history for this paper is available online. To view these files, please visit the journal online (http://dx.doi org/10.1136/bmjopen-2020037192).

Received 22 January 2020 Revised 09 July 2020 Accepted 06 August 2020

Check for updates

(c) Author(s) (or their employer(s)) 2020. Re-use permitted under CC BY-NC. No commercial re-use. See rights and permissions. Published by BMJ.

${ }^{1}$ Department of Orthopedics, Trauma and Hand Surgery, Chemnitz Hospital, Chemnitz, Sachsen, Germany

${ }^{2}$ Center for Complementary

Medicine, Institute for Infection

Prevention and Hospital

Epidemiology, Medical Center University of Freiburg, Faculty of Medicine, University of Freiburg,

Freiburg, Baden-Württemberg,

Germany

${ }^{3}$ Chirurgische Klinik,

Evangelisches

Diakoniekrankenhaus Freiburg,

Freiburg, Baden-Württemberg,

Germany

Correspondence to Dr Ann-Kathrin Lederer; ann-kathrin.lederer@uniklinikfreiburg.de

\section{ABSTRACT}

Objectives Complementary and alternative medicine (CAM) is frequently used in Western countries within general medicine and internal medicine. Information on the use in orthopaedic and trauma surgery is widely lacking. The aim of this study was to investigate usage and needs regarding CAM for these patients.

Design Prospective paper-based, pseudoanonymous, cross-sectional survey.

Setting From August to December 2018, a questionnaire composed of 17 questions was distributed to all eligible patients.

Participants In-house patients in orthopaedic and trauma surgery at a high-volume medical centre in Germany.

Primary and secondary outcome measures Previous or current usage of CAM, interest and requests towards CAM as well as communication about CAM.

Results Overall, 457 orthopaedic and trauma surgical patients took part in the survey. They were on average 52 years old and $54 \%$ were male. Most of the patients were admitted due to bone fractures and most underwent operative therapy. Previous or current CAM usage was stated by $76 \%$ and $30 \%$ of patients, respectively. Most of the patients stated to be interested in usage of CAM and demanded for more clinical usage of CAM and reliable information about CAM. More than $90 \%$ of patients did not discuss CAM interest or usage with their treating physicians. Patients stated that physicians should have knowledge about CAM. They wish to be treated in a holistic manner and want to strengthen self-efficacy.

Conclusions Usage of CAM of patients in orthopaedic and trauma surgery appears to be high. Only a few patients discuss their interest and usage of CAM with their treating physician. Therefore, surgeons should ask their patients about CAM and should consider evidence-based CAM approaches for complementary treatment.

Trial registration number DRKS0001544.

\section{BACKGROUND}

Complementary and alternative medicine (CAM) is a general term comprising a variety of diverse therapeutic approaches, which are not considered as a part of conventional medicine. Popular and commonly known examples are acupuncture as a part of the traditional Chinese medicine (TCM), phytotherapy, naturopathy and homeopathy as

\section{Strengths and limitations of this study}

In the absence of a validated questionnaire for orthopaedic and trauma patients, a modified version of a previously used questionnaire was used.

- The high response rate of the survey strengthens the results.

- The survey might not be representative for the remaining parts of Germany and other countries as it was limited to one single area.

well as anthroposophic medicine. CAM is mostly used to complement conventional therapy and many CAM treatments contain elements to support self-efficacy of patients. ${ }^{1}$ Many patients use CAM independently and without prior consultation of a physician. ${ }^{23}$ Patients often consider CAM as safe, natural and devoid of harmful potential. ${ }^{4}$ Patients' aims for usage of CAM are diverse: it is widely used in patients with non-life-threatening and self-limiting diseases such as respiratory and gastrointestinal infections. ${ }^{5}$ But CAM is also popular in patients with chronic and life-limiting diseases like cancer. ${ }^{6}$ Meanwhile, methods of CAM with proven evidence have found their way into various official treatment guidelines in Germany, ${ }^{78}$ some of them are also related to relief of pain. ${ }^{910}$ In the field of orthopaedic and trauma surgery CAM treatments have been found to be efficacious, for example, in chronic non-specific back pain and osteoarthritis of the knee. ${ }^{11}{ }^{12}$ However, less is known about the frequency of interest and usage of CAM in orthopaedic and trauma surgical patients. Communication about CAM between attending physicians and patients appears to be poor; more than $80 \%$ of patients with cancer from Switzerland were not asked about usage of CAM. ${ }^{4}$ While it tells the physician about health-related beliefs and preferences of the patient, which is important for good adherence and a patient-centred treatment, information about CAM use may 


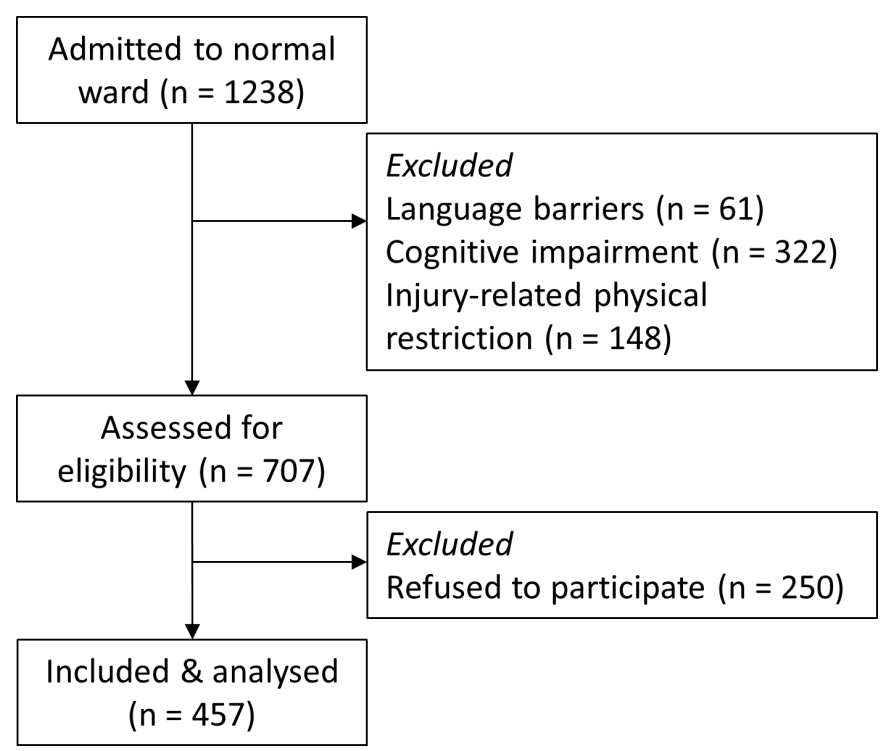

Figure 1 Process of screening, including and analysis of participants.

also be a safety issue. Improper CAM usage means a financial burden for patients and may cause inappropriate side effects and interactions with conventional medications, especially what herbal medicine is regarded. ${ }^{413}$ This study aimed to evaluate the usage and demands regarding CAM in patients referred to a department of orthopaedics and trauma treatment.

\section{METHODS}

Between August and December 2018 a monocentric, paper-based, cross-sectional survey among orthopaedic and trauma patients at a German Medical Center was conducted. Written consent was obtained for all participants. All orthopaedic and trauma surgical patients of all ages, all diagnoses and all treatments (surgical and non-surgical), who were admitted for inpatient treatment to the Department of Orthopedics, Trauma and Hand Surgery at the Medical Center, were consecutively screened for eligibility. Reasons for exclusion were cognitive impairment and inability to communicate (eg, language barriers or due to physical condition). Outpatients and patients staying in intensive care unit were not considered. Patients received the questionnaire by an admission nurse during their admission procedure. To avoid response bias patients were asked to complete the questionnaire independently and on their own and return it pseudonymised to the nursing staff after finishing.

\section{Questionnaire}

In the absence of a validated questionnaire for orthopaedic and trauma patients, a modified version of a questionnaire was used, which was recently developed by the academic centre for complementary and integrative medicine of the German state Baden-Württemberg (AZKIM, www.azkim.de) for a CAM survey among inpatients of four German university hospitals. ${ }^{14}$ The questionnaire contained 17 questions which are related to sociodemographic aspects (insurance, age and gender), diagnosis (reason for hospitalisation) and planned therapy. In a next set of questions the knowledge and usage of different types of CAM is respected. Current usage of CAM was asked by a yes-no question. Further questions are on reasons for usage and experience with currently used CAM as well as reasons for non-usage of CAM and about communication between patients and their attending physician about CAM usage. At the end, all patients had to state what is subjectively of importance for their treatment and what they would desire during hospital stay. The questionnaire is only available in German.

\section{Statistics}

Population size and an error probability of $5 \%$ for a $95 \%$ CI led to a calculated sample size of 384 patients. Since it was expected that a substantial number of admitted patients would not be willing to consent to the study, the number of cases was adjusted to 960 persons covering a non-participation rate of $60 \%$. Questionnaires were numbered in sequence. Data were transferred in a preformed table (Microsoft Excel) by two authors. The database was closed before analysis of the data. Analysis was performed using IBM SPSS (V.25.0). Descriptive analysis was performed for the whole cohort including all patients. Results are expressed as absolute values and percentage of patients, who answered the question (missing data were not interpolated). For analysing influencing factors (gender, health and insurance status) on dichotomous variable 'current CAM usage' logistic regression was performed. For subgroup comparison ( $>65$ years vs $\leq 65$ years, male vs female) $\chi^{2}$ test or, in case of small sample numbers, Fisher's exact tests were used. $\mathrm{P}<0.05$ was considered as significant.

\section{Patient and public involvement}

Patients or the public were not involved in the design, or conduct, or reporting, or dissemination plans of our research.

\section{RESULTS}

A total of 457 out of 1238 admitted patients (37\%) could be included into the study, answered the questionnaire and were analysed (see figure 1). Reasons for exclusion were cognitive impairment $(n=322)$, injury-related physical restriction $(n=148)$ and language barriers $(n=61)$. Two hundred and fifty patients refused to participate. Sociodemographic aspects of included patients are shown in table 1 . Two hundred and forty-seven $(54 \%)$ were male and $196(43 \%)$ were female. Fourteen patients (3\%) did not state their gender. Patients were on average 52 (range $17-93$ ) years old. Only $9 \%$ ( $n=39$, always percentage of patients, who answered the question) of the patients had a private health insurance. Occurrence of bone fracture $(\mathrm{n}=165,37 \%)$ was the most common reason for hospital admission. More than $70 \%$ of the patients $(n=317,72 \%)$ 
Table 1 Health insurance status, reason for admission and planned therapy of study participants

\begin{tabular}{lc}
\hline & n (\%) \\
\hline Gender & $247(54)$ \\
\hline Male & $196(43)$ \\
\hline Female & $14(3)$ \\
\hline Not stated & \\
\hline Status of health insurance & $400(91)$ \\
\hline Statutory & $30(7)$ \\
\hline Private & $9(2)$ \\
\hline Supplementary & \\
\hline Reason for admission & $3(1)$ \\
\hline Chronic back pain & $15(3)$ \\
\hline Acute back pain & $165(37)$ \\
\hline Bone fracture & $29(6)$ \\
\hline Ligament injury & $3(1)$ \\
\hline Metastatic cancer with bone lesions & $10(2)$ \\
\hline Endoscopic examination of a joint & $16(4)$ \\
\hline Joint replacement & $16(4)$ \\
\hline Concussion & $127(28)$ \\
\hline Accident & $65(14)$ \\
\hline Other* & \\
\hline Planned therapy & $64(17(72)$ \\
\hline Operation & \\
\hline Not operative & \\
\hline I don't know & \\
\hline Result are & \\
\hline
\end{tabular}

Results are expressed as absolute values and percentage of patients who answered the question.

*Main reasons were removal of metal plates and other implants after surgery as well as inflammation of joints and tendon and shoulder injury.

underwent operative therapy during their hospital stay. Almost $90 \%$ of patients $(88 \%, \mathrm{n}=377)$ were hospitalised for emergency reasons.

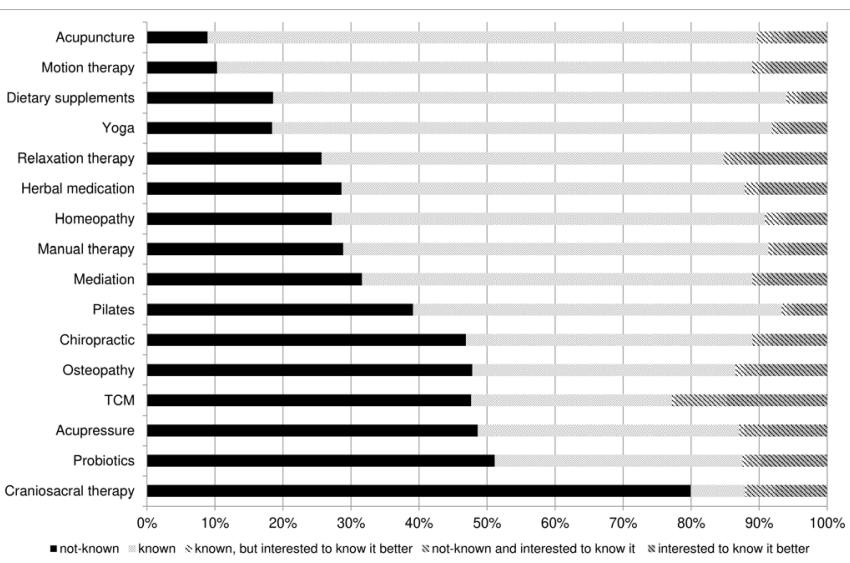

Figure 2 Popularity of complementary and alternative medicine (CAM) and interest in getting more knowledge about CAM. TCM, traditional Chinese medicine.

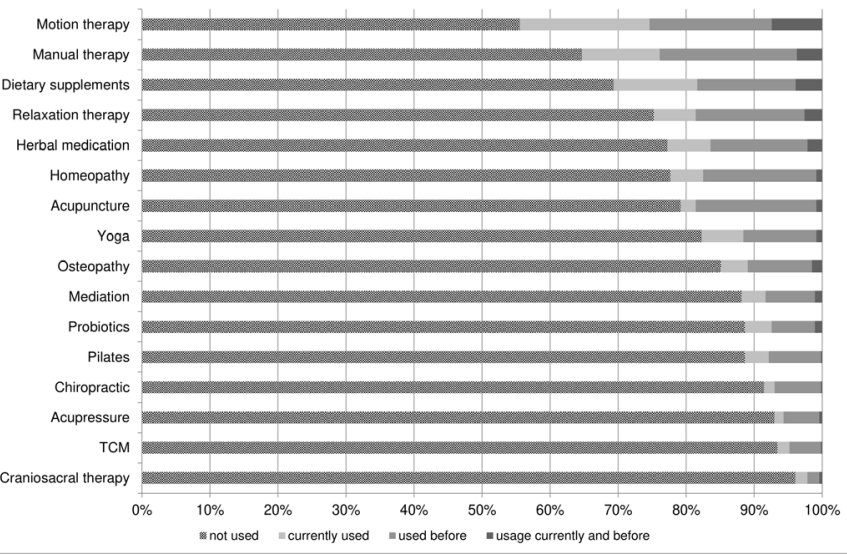

Figure 3 Previous and current usage of complementary and alternative medicine (CAM). TCM, traditional Chinese medicine.

\section{Popularity of CAM}

Summary of results visualising popularity of CAM and interest in getting more knowledge about CAM is shown in figure 2. The most known therapy was acupuncture $(\mathrm{n}=353,81 \%)$, followed by motion therapy $(\mathrm{n}=336,79 \%)$, dietary supplements $(n=313,75 \%)$ and yoga $(n=307$, $73 \%)$. Least known were craniosacral therapy $(\mathrm{n}=31$, $8 \%)$, TCM $(\mathrm{n}=120,29 \%)$, probiotics $(\mathrm{n}=146,36 \%)$ and acupressure $(\mathrm{n}=154,38 \%)$. Patients were most interested in learning about TCM $(\mathrm{n}=93,23 \%)$. Patients added sporadically further approaches such as reflexology, hiking, fascial treatment, kinesiology, cupping, neural therapy and Feldenkrais.

Frequency of usage of different types of CAM is shown in figure 3 . All in all, $76 \%$ of patients $(n=347)$ have been currently or in the past been using one or several of the listed CAM therapies, 30\% ( $\mathrm{n}=139)$ were currently using CAM (figure 3). Most commonly used therapy currently or in the past was motion therapy $(n=203,44 \%)$, followed by manual therapy $(\mathrm{n}=161,35 \%)$ and dietary supplements $(\mathrm{n}=140,31 \%)$. Only a few patients used craniosacral therapy $(\mathrm{n}=18,4 \%)$, TCM $(\mathrm{n}=30,7 \%)$ and acupressure $(\mathrm{n}=32,7 \%)$.

Table 2 shows current usage of different CAM approaches and distinguishes patients who use CAM due to their current hospitalisation complaint, and patients who use CAM due to other reasons. The most currently used approaches due to their current hospitalisation complaint were motion therapy $(15 \%, \mathrm{n}=66)$ and manual therapy $(9 \%, \mathrm{n}=39)$. Overall, besides motion therapy $(23 \%, \mathrm{n}=107)$ and manual therapy $(13 \%, \mathrm{n}=61)$, the most commonly used approach was application of dietary supplements $(14 \%, \mathrm{n}=65)$.

\section{Patients' requests}

Patients' requests regarding CAM are shown in figure 4. Almost $80 \%$ of patients stated that physicians should have knowledge about CAM ( $\mathrm{n}=282,77 \%)$. CAM consultation $(\mathrm{n}=281,76 \%)$ as well as more information about selfefficacy $(n=330,86 \%)$ was desired by most of the patients 


\begin{tabular}{lcc}
$\begin{array}{l}\text { Table } 2 \\
\text { current hospitalisation }\end{array}$ & \multicolumn{2}{l}{ Current CAM usage in relation to reason for } \\
\hline $\begin{array}{l}\text { Application due to current } \\
\text { hospitalisation complaint }\end{array}$ & Yes; n (\%) & No; n (\%) \\
\hline Acupuncture & $4(1)$ & $7(2)$ \\
Acupressure & $3(1)$ & $4(1)$ \\
Homeopathy & $7(2)$ & $16(4)$ \\
Motion therapy & $66(15)$ & $41(9)$ \\
Relaxation therapy & $11(2)$ & $21(5)$ \\
Meditation & $5(1)$ & $13(3)$ \\
Osteopathy & $8(2)$ & $15(3)$ \\
Manual therapy & $39(9)$ & $22(5)$ \\
Chiropractic & $2(1)$ & $6(1)$ \\
Craniosacral therapy & $2(1)$ & $7(2)$ \\
Phytotherapy & $2(1)$ & $21(5)$ \\
TCM & $1(1)$ & $7(2)$ \\
Yoga & $7(2)$ & $22(5)$ \\
Pilates & $4(1)$ & $13(3)$ \\
Dietary supplements & $18(4)$ & $47(10)$ \\
Probiotics & $6(1)$ & $14(3)$ \\
\hline
\end{tabular}

Results are expressed as absolute values and percentage of patients who answered the question; multiple-answer question-patients could choose more than one approach. CAM, complementary and alternative medicine; TCM, traditional Chinese medicine.

during their hospital stay. Treatment in holistic manner would be desirable for more than $80 \%$ of the patients $(\mathrm{n}=312,83 \%)$, and almost $90 \%$ stated that they want to make their own decision about therapy $(n=318,87 \%)$. Also the patients desired that CAM should be covered by their health insurances. Hospitalised patients wish for more usage of CAM therapies as popularity of all mentioned approaches shown in figure 5 was more than $65 \%$. Most popular were pain therapy $(\mathrm{n}=292,86 \%)$ and motion therapy $(\mathrm{n}=305,87 \%)$.

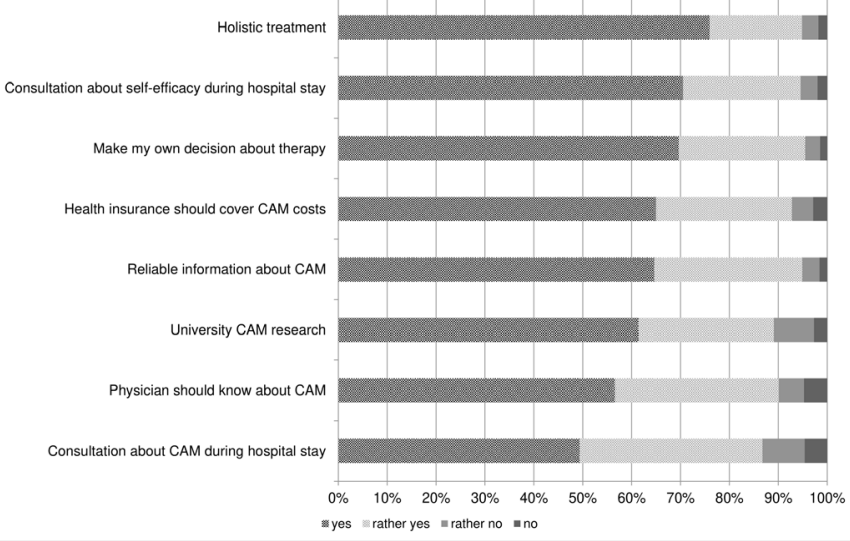

Figure 4 Patients' treatment requests. CAM, complementary and alternative medicine.

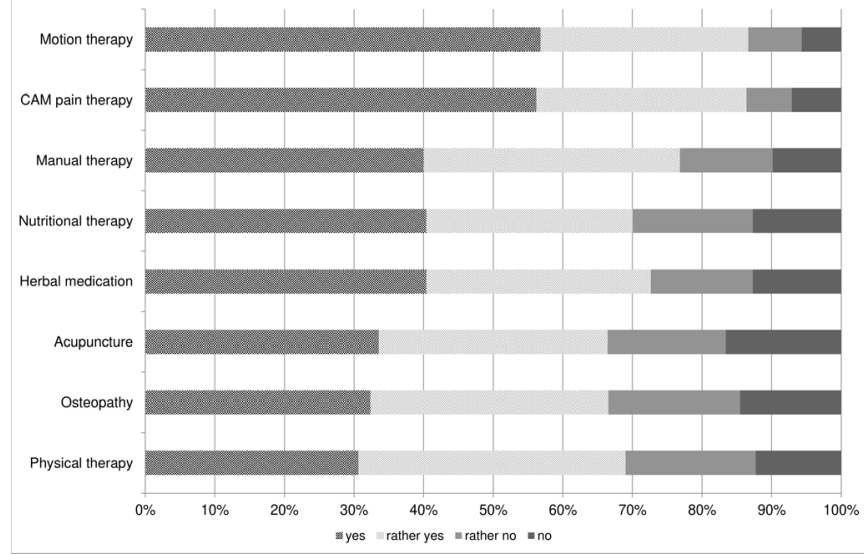

Figure 5 Request for complementary and alternative medicine (CAM) during hospital stay.

University CAM research is supported by more than $70 \%(\mathrm{n}=261,73 \%)$. More than $80 \%$ of patients $(\mathrm{n}=298$, $83 \%$ ) wish for reliable information about CAM.

\section{Patients with previous and current usage of CAM}

Comparison of sociodemographic aspects of patients with $(n=163)$ and without $(n=294)$ current usage of CAM is shown in table 3 . There was a higher percentage of females in the group with CAM usage (49\% vs $40 \%$, $\mathrm{p}=0.046)$. Other sociodemographic aspects were not different between the groups. Reasons for usage of CAM were body strengthening and health preservation $(\mathrm{n}=123$, $91 \%)$ and body support $(\mathrm{n}=123,89 \%)$. Only $23(21 \%)$ patients stated that they used CAM because conventional therapy was ineffective and $42(35 \%)$ patients reported to use CAM exclusively. CAM is perceived as a gentle therapeutic approach by more than half of the patients $(n=73$, $63 \%)$, and more than $90 \%$ of patients $(n=112)$ rated CAM therapies as harmless. The most common reason for termination of CAM usage was no further need of CAM in 78 patients $(79 \%)$, followed by no or small effectiveness in 16 patients $(39 \%)$ and too expensive therapy costs in 26 patients (37\%). Figure 6 shows the experience of patients with CAM. Side effects occurred in $16(13 \%)$ patients, but only nine of them terminated CAM usage. More than $90 \%$ of patients $(n=119)$ would recommend CAM usage and almost $90 \%$ were satisfied with it $(n=113$, $89 \%$ ). Most of the patients stated recommendation for CAM usage was given by family doctors, other non-surgical attending physicians, physiotherapists or nurses $(n=55$, $42 \%$ ), followed by recommendation of family and friends $(\mathrm{n}=36,27 \%)$. Media such as journals, internet or social media were used by 23 patients (18\%). Alternative practitioners were only consulted by nine patients $(7 \%)$. Less than $30 \%$ of patients with current CAM usage stated that they told their attending physician about CAM interest $(n=28)$ and CAM usage $(n=27)$. Reasons for not speaking of these patients were the feeling that there was no time for talking about it $(n=58,56 \%)$ or an expectation of physicians' negative attitude towards CAM usage $(n=21$, $23 \%$ ) or that physician was the wrong contact regarding 
Table 3 Subgroup analysis: sociodemographic differences of patients with and without current usage of CAM

\begin{tabular}{|c|c|c|c|}
\hline & $\begin{array}{l}\text { With CAM } \\
(n=163)\end{array}$ & $\begin{array}{l}\text { Without CAM } \\
(\mathrm{n}=294)\end{array}$ & $P$ value \\
\hline $\begin{array}{l}\text { Sex (n male/female, } \\
\% \text { ) }\end{array}$ & $81 / 78(51 / 49)$ & $\begin{array}{l}151 / 101 \\
(60 / 40)\end{array}$ & 0.046 \\
\hline Age (years, range) & $52(17-92)$ & $52(17-93)$ & 0.954 \\
\hline \multicolumn{4}{|l|}{ Insurance, n (\%) } \\
\hline Statutory & $146(92)$ & $228(92)$ & 0.806 \\
\hline Private & $10(6)$ & $18(7)$ & \\
\hline Supplementary & $3(2)$ & $3(1)$ & \\
\hline $\begin{array}{l}\text { Reason of } \\
\text { admission, } \mathrm{n}(\%)\end{array}$ & & & 0.707 \\
\hline Chronic back pain & $2(1)$ & $0(0)$ & \\
\hline Acute back pain & $5(3)$ & $6(2)$ & \\
\hline Bone fracture & $65(40)$ & $90(35)$ & \\
\hline Ligament injury & $9(6)$ & $18(7)$ & \\
\hline $\begin{array}{l}\text { Metastatic cancer } \\
\text { with bone lesions }\end{array}$ & $1(1)$ & $2(1)$ & \\
\hline $\begin{array}{l}\text { Endoscopic } \\
\text { examination of a joint }\end{array}$ & $4(3)$ & $6(2)$ & \\
\hline Joint replacement & $7(4)$ & 7 (3) & \\
\hline Concussion & $6(4)$ & $10(4)$ & \\
\hline Accident & $41(25)$ & $76(30)$ & \\
\hline Other & $21(13)$ & 40 (16) & \\
\hline Planned therapy & & & 0.214 \\
\hline Operation & $110(70 \%)$ & $186(75 \%)$ & \\
\hline Not operative & $19(12 \%)$ & $34(14 \%)$ & \\
\hline I don’t know & $28(18 \%)$ & $29(11 \%)$ & \\
\hline
\end{tabular}

Results are expressed as absolute values and percentage of patients who answered the question.

CAM, complementary and alternative medicine.

CAM (n=16, 17\%). Only 12 patients (17\%) stated an expected incompetence of the physician.

Of all patients with CAM experience only $15 \% \quad(n=42)$ reported usage of CAM to their attending physician.

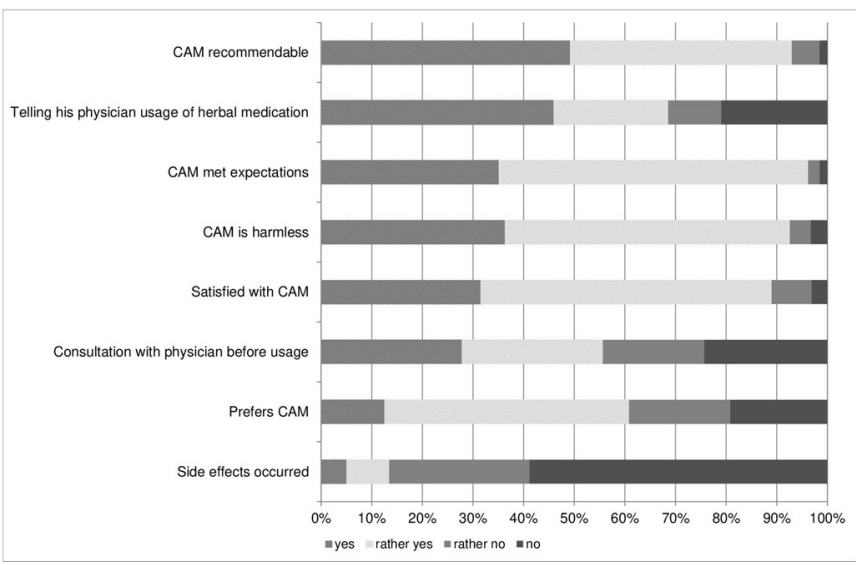

Figure 6 Attitude towards complementary and alternative medicine (CAM) and experience with previously used CAM.
Reasons were the feeling that there was no time for talking about it $(n=120,49 \%)$ or an expectation of physicians' negative attitude towards CAM usage $(n=35,16 \%)$ or that physician was the wrong contact regarding CAM $(n=65$, $30 \%)$. Only $10 \%(n=22)$ stated an expected incompetence of the physician. Patients added further reasons for not speaking about CAM interest and usage: no current need for CAM usage $(n=25)$, no knowledge of CAM possibility $(n=23)$ and no interest regarding CAM $(n=5)$. Overall, only $12 \%(n=44)$ of all patients, who answered questions about interest and usage of CAM (including also patients without knowledge of CAM experience), reported that they told their attending physician about CAM interest and only $12 \%(n=45)$ told their physician about usage of CAM.

\section{Reasons for non-usage of CAM}

Two hundred and sixty (41\%) patients stated current non-usage of CAM. Reported reasons were no necessity for CAM $(\mathrm{n}=175,67 \%)$, not knowing of CAM possibility $(n=103,40 \%)$, doubt about efficacy $(n=63,24 \%)$, as well as too high costs of CAM $(n=63,24 \%)$ and no current interest in CAM usage $(n=50,19 \%)$. Thirty-one $(12 \%)$ patients stated to be afraid of side effects. Patients added further reasons: lack of CAM offering $(n=7)$ and not the right time for CAM usage $(n=4)$.

\section{Subgroup analysis: influence of gender, age and health insurance status}

Logistic regression analysis showed no significant influence of age, gender and health insurance status on current CAM usage. The elderly (>65 years) had slightly less CAM usage compared with younger patients $(36 \%$ vs $39 \%$ ), and all queried approaches of CAM were less known in the elderly. Large differences of knowledge were found in meditation (30\% vs 66\%), chiropractic (23\% vs $49 \%)$, yoga ( $51 \%$ vs $79 \%$ ) and Pilates (29 vs $61 \%)$. Interest in getting more familiar with CAM was slightly higher in the elderly (mean of all approaches: $13 \%$ vs $11 \%$ ). Discussion of interest and usage of CAM with physicians was more common in the population aged 65 years and older than in younger patients. Most CAM approaches were quite equally known by both sexes. Relaxation therapy was slightly more known in female than in male patients $(67 \%$ vs $53 \%)$. Interest in getting more familiar with different CAM approaches was similar in both sexes, but females wished also for more usage of CAM during hospital stays. Women used more frequently homeopathy $(29 \%$ vs $17 \%)$, relaxation techniques (30\% vs $20 \%)$, manual therapy $(42 \%$ vs $30 \%)$, yoga $(27 \%$ vs $10 \%)$ and dietary supplements $(36 \%$ vs $26 \%)$ than men. Consultations about CAM (52\% vs $35 \%)$ and self-efficacy ( $70 \%$ vs $58 \%$ ) as well as a holistic treatment (72 vs $61 \%$ ) were more frequently favoured by women. More female than male patients wished for more authority regarding their therapeutic decisions ( $72 \%$ vs $58 \%$ ). 


\section{DISCUSSION}

To our knowledge, this is the first study investigating the demand and usage of CAM in orthopaedic and trauma patients in Germany showing previous or current CAM usage in $76 \%$ and $30 \%$ of patients, respectively. Most of the patients stated an interest towards CAM underlining that CAM is also of interest in surgical patients. However, the results of surveys, especially of ones including retrospective questions, are always limited due to response bias and recall bias. Inclusion and exclusion criteria of our study were thoroughly chosen to ensure that patients had to be able to fill the questionnaire independently and on their own to avoid influence of relatives and nursing staff. But even though the questionnaire information text emphasised that the questionnaire did not affect medical treatment, patients' expectation that questionnaire might have an impact on their medical care could bias their response. Aiming to map also the experience with CAM in the past, the questionnaire asked for previous usage of CAM, making the results susceptible for a not avoidable recall bias. However, the observed CAM experience rate of $76 \%$ is similar to results of other surveys in Germany. ${ }^{5}$ It is assumed that the CAM experience rate of surgical patients did not differ from the rate of the general German population. Strength of our survey is a robust response rate of $65 \%$, which was higher than expected. Surveys in surgical patients are rare and the response rate is often lower than $30 \% \cdot{ }^{15-17}$ The observed current usage rate of CAM in our study is in line with results of our studies, supporting validity of our study: A Canadian survey investigated the current usage of CAM in hepatobiliary surgical patients and found a usage rate of $27 \%$ summarising a rate of $21 \%$ in patients without cancer and of $34 \%$ in patients with cancer. ${ }^{18}$ Soós et al found a current CAM usage rate of patients underwent surgery at the Department of Surgery of the Semmelweis University, Hungary of $27 \%$, whereof higher rates were observed in patients with cancer. ${ }^{17}$ An American survey showed a current CAM usage rate of $25 \%$ in surgical patients. ${ }^{19}$ Summing up, it appears that nearly a third of surgical patients use CAM even during surgical treatment. But it has to be taken into account that patients without CAM interest may not fill in a questionnaire towards CAM provoking false result of higher CAM usage rates. Nevertheless, as ours and other surveys in non-surgical patients show, patients often use CAM by themselves and without prior consultation of their attending physicians but desire that their physicians know about CAM. ${ }^{2320}$ Communication on CAM was poor not only in our study. Most studies reported only one-third of patients informing their attending physician about usage of CAM. ${ }^{2152122}$ Soós et alfound an even lower rate of $20 \%$ in surgical patients. ${ }^{17}$ In our study, just a few patients told their attending surgeons about CAM, often because they thought that there is no time for it. Whether this is a safety risk or not can, to the present knowledge, only be speculated, because reliable data on the risk of non-communicated CAM are lacking. At least for herbal preparations, which in rare cases can cause interactions with conventional medicine or can interfere with coagulation, ${ }^{132324}$ a more open communication would be desirable. The lack of communication might also explain the gap between interest and usage of CAM. Interest in CAM was clearly bigger than usage of CAM in our study. Similar observations were also made by others emphasising the importance of reliable CAM information for patients. ${ }^{15} 17$ Wang et alalso reported that patients who were not willing to incorporate CAM might be changing their mind, if a physician would provide them reliable information about CAM underlining the importance of physicians' before mentioned desired knowledge about CAM. ${ }^{19}$ Patients using CAM reported that CAM was recommended by their attending physician or other medical staff such as physiotherapist. Other studies indicate that the strongest influence on patients regarding usage of CAM was given by family and friends as well as attending physicians. ${ }^{19} 20$ Additionally, the demand of patients to be more included in the decision-making process of therapy appears to be very high, as in our cohort more than $90 \%$ claimed to have authority.

Interestingly, it appears that CAM interest exists also in urgent condition as almost $90 \%$ of our study patients were treated due to emergency reasons. Schieman et al reported that one of the most common causes for CAM usage in surgical patients was boosting of energy. ${ }^{18}$ Bauer et al found that more than $80 \%$ of patients with cancer from a self-help group were interested in CAM in order to strengthen body's own healing forces. ${ }^{15}$ This is in accordance with our results, as CAM users mostly stated that they do it to strengthen their healing capacity and resistance. The preferred CAM methods appear to vary according to different indications. Not surprising, patients with orthopaedic diseases favour motion and manual therapies, whereas patients with cancer often prefer herbal medications and relaxation therapies. ${ }^{1518} 20$ Different from the results of others, chiropractic played only a minor role in our cohort. Especially, studies from Northern America indicate higher usage rates of chiropractic indicating regional differences of preferred CAM approaches and limiting our results' transferability. ${ }^{18} 19$ The frequency of CAM usage might also be affected by patients' health insurance status. ${ }^{4}$ Private and statutory health insurances are covering different costs of CAM in Germany. Our study shows a slightly lower rate of private health insurance $(7 \%)$ compared with overall private health insurance rate in Germany ( $7 \%$ vs $12 \%$ as reported in 2017). ${ }^{25}$ Health insurance status in Germany depends on patients' income and the trial hospital is located in an area with a lower than average income. ${ }^{26}$ Therefore, the difference might be attributable to the income of the patients. As mentioned before, the results of the survey might not be transferable as it was limited to one single location. Additionally, it did not ask for further, potentially influencing sociodemographic differences such as educational status and nationality. The seen bigger interest of women in CAM has been reported in many publications and could be confirmed by our results ${ }^{2151720}$ but the difference was 
only small, and the result of subgroup analysis is always limited by its exploratory character showing just tendencies for further research. Despite all before mentioned limiting factors, the survey indicates that CAM appears to be of importance for surgical patients. For promoting an integrative surgery, further research is needed to investigate clinical relevance and applicability of CAM in surgery.

\section{CONCLUSION}

This study was able to show interest of surgical patients regarding CAM in Germany. It emphasises the importance of physicians' knowledge of CAM nowadays. As the percentage of CAM users among orthopaedic and trauma patients is substantial and the need for information about CAM is high it would, from a patient-centred perspective, be desirable if also surgeons and specialists in orthopaedics are informed about CAM options in their field or at least can refer patients to physicians who are qualified in CAM. Additionally, only a few patients discuss their interest and usage of CAM with their attending physician indicating the necessity to actively ask surgical patients for usage of CAM to recognise potential interaction effects of CAM on conventional treatment.

Acknowledgements The article processing charge was funded by the BadenWuerttemberg Ministry of Science, Research and Art and the Albert Ludwigs University Freiburg in the funding programme Open Access Publishing.

Contributors AK, RH and AKL are responsible for conception and design. Raw data were acquired by AK, NR and LS. Data were analysed by AM and AKL. Statistical analysis was performed by AM and AKL. AKL wrote the manuscript with help of AK. LS and $\mathrm{RH}$ revised the article.

Funding The authors have not declared a specific grant for this research from any funding agency in the public, commercial or not-for-profit sectors.

Competing interests None declared.

Patient consent for publication Not required.

Ethics approval The study was approved by the local ethical committee (EK-BR49/18-1) and was conducted according to the Declaration of Helsinki.

Provenance and peer review Not commissioned; externally peer reviewed.

Data availability statement Data are available upon reasonable request. Data are available upon reasonable request to all interested researchers.

Open access This is an open access article distributed in accordance with the Creative Commons Attribution Non Commercial (CC BY-NC 4.0) license, which permits others to distribute, remix, adapt, build upon this work non-commercially, and license their derivative works on different terms, provided the original work is properly cited, appropriate credit is given, any changes made indicated, and the use is non-commercial. See: http://creativecommons.org/licenses/by-nc/4.0/.

ORCID iD

Ann-Kathrin Lederer http://orcid.org/0000-0001-7984-9530

\section{REFERENCES}

1 Tong Y, Chai L, Lei S, et al. Effects of tai chi on self-efficacy: a systematic review. Evid Based Complement Alternat Med 2018;2018:1701372:1-21.

2 Wortmann JK, Bremer A, Eich HT, et al. Use of complementary and alternative medicine by patients with cancer: a cross-sectional study at different points of cancer care. Med Oncol 2016;33:78.
3 Foley $\mathrm{H}$, Steel A, Cramer $\mathrm{H}$, et al. Disclosure of complementary medicine use to medical providers: a systematic review and metaanalysis. Sci Rep 2019;9:1573.

4 Jermini M, Dubois J, Rodondi P-Y, et al. Complementary medicine use during cancer treatment and potential herb-drug interactions from a cross-sectional study in an academic centre. Sci Rep 2019;9:5078.

5 Institut für Demoskopie Allensbach. Naturheilmittel 2010 - ergebnisse einer bevölkerungsrepräsentativen befragung, 2010. Available: http:// www.ifd-allensbach.de/uploads/tx_studies/7528_Naturheilmittel_ 2010.pdf [Accessed 9 May 2017].

6 Horneber M, Bueschel G, Dennert G, et al. How many cancer patients use complementary and alternative medicine: a systematic review and metaanalysis. Integr Cancer Ther 2012;11:187-203.

7 Deutsche Schmerzgesellschaft. Definition, pathophysiologie, diagnostik und therapie des fibromyalgiesyndroms, 2017. Available: http://www.awmf.org/leitlinien/detail/l//145-004.html [Accessed 15 Nov 2017].

8 Becker A, Becker M, Engeser P. Leitlinie: chronischer schmerz, 2013. Available: http://www.awmf.org/uploads/tx_szleitlinien/053-036I_S1_ Chronischer_Schmerz_2013-10.pdf

9 Ficke JR, Moroski NM, Ross SD, et al. Integrative medicine as an adjunct to orthopaedic surgery. J Am Acad Orthop Surg 2018;26:58-65.

10 Lou Galantino M, Boothroyd C, Lucci S. Complementary and alternative medicine interventions for the orthopedic patient: a review of the literature. Seminars Integr Med 2003;1:65-79.

11 Chou R, Deyo R, Friedly J, et al. Nonpharmacologic therapies for low back pain: a systematic review for an American College of physicians clinical practice guideline. Ann Intern Med 2017;166:493.

12 Yang M, Jiang L, Wang Q, et al. Traditional Chinese medicine for knee osteoarthritis: an overview of systematic review. PLoS One 2017;12:e0189884.

13 Lederer A-K, Schmucker C, Kousoulas L, et al. Naturopathic treatment and complementary medicine in surgical practice. Dtsch Arztebl Int 2018;115:815-21.

14 Lederer A-K, Samstag Y, Joos S. Demand on complementary medicine of patients and medical staff at the university hospital freiburg, heidelberg, tübingen and ulm - a survey study of the academic center for complementary and integrative medicine (AZKIM), 2018. Available: https://www.drks.de/drks_web/ PdfDownstreamServlet?ID=DRKS00015445\&LOCALE=en [Accessed 6 Aug 2019].

15 Bauer F, Schmidt T, Eisfeld H, et al. Information needs and usage of complementary and alternative medicine in members of a German self-help group for gastrointestinal stroma tumours, sarcoma, and renal cancer. Complement Ther Med 2018;41:105-10.

16 Höfer J, Hoffmann F, Kamp-Becker I, et al. Complementary and alternative medicine use in adults with autism spectrum disorder in Germany: results from a multi-center survey. BMC Psychiatry 2019;19:53.

17 SÁ S, Jeszenői N, Darvas K, et al. Nem konvencionális gyógymódok használata sebészeti betegek között. Orv Hetil 2016;157:1483-8.

18 Schieman C, Rudmik LR, Dixon E, et al. Complementary and alternative medicine use among general surgery, hepatobiliary surgery and surgical oncology patients. Can J Surg 2009;52:422-6.

19 Wang S-M, Caldwell-Andrews AA, Kain ZN. The use of complementary and alternative medicines by surgical patients: a follow-up survey study. Anesth Analg 2003;97:1010-5.

20 Schuerger N, Klein E, Hapfelmeier A, et al. Evaluating the demand for integrative medicine practices in breast and gynecological cancer patients. Breast Care 2019;14:35-40.

21 Lazarou R, Heinrich M. Herbal medicine: who cares? the changing views on medicinal plants and their roles in British lifestyle. Phytother Res 2019;33:2409-20.

22 Zahn R, Perry N, Perry E, et al. Use of herbal medicines: pilot survey of UK users' views. Complement Ther Med 2019;44:83-90.

23 NHS. Herbal medicines, 2019. Available: https://www.nhs.uk/ conditions/herbal-medicines/ [Accessed 30 Jul 2019].

24 Wang C-Z, Moss J, Yuan C-S. Commonly used dietary supplements on coagulation function during surgery. Medicines 2015;2:157-85.

25 Bundesministerium für Gesundheit. Daten des Gesundheitswesens, 2017.

26 Statistisches Bundesamt. Einkommen, einnahmen und ausgaben in den gebietsständen, 2017. Available: https://www.destatis. de/DE/Themen/Gesellschaft-Umwelt/Einkommen-KonsumLebensbedingungen/Einkommen-Einnahmen-Ausgaben/Tabellen/ liste-gebietsstaende.html [Accessed 25 Jul 2019]. 